\title{
Preparation and Characterization of ZnSe/EVA Nanocomposites for Photovoltaic Modules
}

\author{
Jose Sebastian', Eby Thomas Thachil1, Jobin Job Mathen², Augustine J. Edakkara3, \\ Nelson Kuriakose ${ }^{3}$, Ginson P. Joseph ${ }^{3 *}$, Joby Sebastian ${ }^{4}$ \\ ${ }^{1}$ Department of Polymer Science \& Rubber Technology, Cochin University of Science and Technology, Kerala, \\ India \\ ${ }^{2}$ Department of Physics, Loyola College, Chennai, Tamilnadu, India \\ ${ }^{3}$ Department of Physics, St. Thomas College, Pala, Kerala, India \\ ${ }^{4}$ Department of Physics, St. Thomas College, Thrissur, Kerala, India \\ Email: "ginsonpj@gmail.com
}

Received 19 May 2015; accepted 26 May 2015; published 29 May 2015

Copyright (C) 2015 by authors and Scientific Research Publishing Inc.

This work is licensed under the Creative Commons Attribution International License (CC BY).

http://creativecommons.org/licenses/by/4.0/

(c) (;) Open Access

\section{Abstract}

ZnSe Nanoparticles were synthesized by solvothermal method and the particle was characterized by Transmission Electron Microscopy. The polymer nanocomposite of $2 \%$ and $4 \% \mathrm{ZnSe} / \mathrm{EVA}$ was fabricated by direct sonicator method. The nanocomposites were characterized by UV-Vis-NIR and FT-IR spectroscopy. The thermal behaviour of the samples was also investigated and we found that the thermal stability of the composites increased with increasing the filler concentrations. The mechanical properties such as tensile strength, peel strength and refractive index of the samples were also studied and reported for the first.

\section{Keywords}

EVA, ZnSe, TG-DTA, Refractive Index, Peel Strength, Tensile Strength

\section{Introduction}

Thermoplastics and thermosetting plastics have been found useful for various applications in the field of electronic and electrical technology. Fabrication of nanostructures in polymer matrices has attracted researchers due to the advantages of readily tunable bandgaps, electroactivity, excellent flexibility and good processability com-

"Corresponding author.

How to cite this paper: Sebastian, J., Thachil, E.T., Mathen, J.J., Edakkara, A.J., Kuriakose, N., Joseph, G.P. and Sebastian, J. (2015) Preparation and Characterization of ZnSe/EVA Nanocomposites for Photovoltaic Modules. Journal of Minerals and Materials Characterization and Engineering, 3, 215-224. http://dx.doi.org/10.4236/immce.2015.34024 
pared with conventional materials [1]-[4]. The optical and electronic properties of the polymer matrices can be altered with judicious selection of nanomaterials [5] [6]. Polymer-semiconductor nanocomposites with non linear optical properties are used in fibre-optic communication systems such as optical storages, optical limiters and digital signal restoration [7]-[9].

Poly Ethylene-co-Vinyl Acetate (EVA) is a commercial plastic with good low temperature flexibility and toughness. EVA exhibits rubbery property of enhanced elongation along with ease of processability of thermoplastics. Due to its surface gloss and impact strength, EVA copolymers find market in film manufacturing. The presence of vinyl acetate molecules in the polymer chain reduces the polymer regularity and crystallinity. EVAclay nanocomposites are widely used in the manufacture of wires, cables and also in food packaging industry [10].

The II-VI semiconducting materials show significant properties from the optoelectronic point of view [11]. Among the polymer -inorganic nanocomposites, $\mathrm{SiO}_{2}, \mathrm{TiO}_{2}, \mathrm{ZnO}$ and clay based filler systems have been widely investigated [12] [13]. In the bulk form and in the quantum dot form, these materials exhibit high density and quantum confinement. Zinc Selenide ( $\mathrm{ZnSe}$ ) is a n-type semiconductor material with wide band gap (2.58 - 2.72 eV) [14] [15]. The band gap was found to increase as the particle size decreased. The mechanical, electrical and thermal properties of EVA-ZnSe nanocomposites were not studied. The incorporation of semiconducting $\mathrm{ZnSe}$ nanoparticles to the amorphous EVA structure was found to alter the properties of the polymer films.

The present work mainly focused on the preparation of nanocomposite film based on EVA with varying ratio of ZnSe particles and studied the effect of ZnSe on the electrical, thermal and mechanical properties of EVA.

\section{Experimental}

\subsection{Synthesis of ZnSe/EVA Nanocomposites}

The materials such as zinc acetate and sodium selenite used for the preparation of ZnSe nanopowder are Merck GR grade of purity $\geq 98 \%$ purity. Zinc acetate of $4.388 \mathrm{~g}$ was dissolved in $100 \mathrm{ml}$ of direct Millipore water and $0.519 \mathrm{~g}$ of sodium selenite $\left(\mathrm{Na}_{2} \mathrm{SeO}_{3}\right)$ was dissolved in $30 \mathrm{ml}$ of hydrazine hydrate $\left(\mathrm{N}_{2} \mathrm{H}_{4} \cdot \mathrm{H}_{2} \mathrm{O}\right)$. Both the prepared solutions were mixed up under vigourous stirring with external heat energy. Then these solutions were transferred into teflon lined sealed stainless steel autoclave and heated at $240^{\circ} \mathrm{C}$ for $5 \mathrm{hrs}$ in a muffle furnace. It was washed two times using Millipore water for removing impurities. In essence, stringent symmetry of nanoparticles can be controlled by chemical concentration, reaction temperature and kinetic control.

Ethylene Vinyl Acetate (EVA), copolymer used for the experiment was obtained from Exxon Mobil Chemicals, Singapore. The vinyl acetate content of the copolymer used was $9.4 \mathrm{wt} \%$ (Density- $0.931 \mathrm{~g} / \mathrm{cm}^{3}$, Melt Flow Index- $2.1 \mathrm{~g} / 10 \mathrm{~min} @ 190^{\circ} \mathrm{C}, 2.16 \mathrm{~kg}$ ). The copolymer was first dissolved in toluene. Then synthesized $\mathrm{ZnSe}$ nanoparticles were dispersed in a sonication bath for 2 hours on the basis of the desired weight fraction $(2 \%$ and $4 \%$ ) of $\mathrm{ZnSe}$ nanoparticle at room temperature. In order to make the resultant neat nanoparticles filled polymer samples, it was transfered to a teflon coated glass mould and spread with uniform thickness. Afterward, the mixture was heated at $40^{\circ} \mathrm{C}$ for 18 hours in an air oven to evaporate the solvent completely and finally, a thin film of pure and $\mathrm{ZnSe} / \mathrm{EVA}$ nanocomposites formed.

\subsection{Characterization}

ZnSe nanoparticles were analyzed using Hitachi H7500 TEM where the sample is irradiated with an electron beam of uniform current density with the electron energy of $100 \mathrm{keV}$. The Fourier transform infrared (FT-IR) spectra of the samples have been carried out in the wave number range $400-4000 \mathrm{~cm}^{-1}$ using a Thermo Nicolet Make Avatar 370 FTIR Spectrometer and for signal detection, DTGS detector is used. The refractive indices of the samples were determined using HIOKI 3532 - 50 LCR IMPEDANCE ANALYZER and program version $4.03 \mathrm{E}$ was used to record the refractive indices of the samples by varying the frequencies from $100 \mathrm{~Hz}$ to $5 \mathrm{MHz}$. VARIAN CARY 5000 spectrophotometer is used to determine the optical absorption spectrum of the samples and recorded in the region of 200 to $2000 \mathrm{~nm}$. The TGA and DTA analyses of ZnSe/EVA were carried out between 28 and $1300^{\circ} \mathrm{C}$ at a heating rate of $20 \mathrm{~K} / \mathrm{min}$ using the instrument NETSZCH STA 409C. The tensile properties of the virgin EVA and EVA nanocomposites were measured by an Instron 3366 universal testing machine according to ASTM D882. Peel strength was performed using an Instron tensile testing machine at a peel speed of $50 \mathrm{~mm} / \mathrm{min}$. Peel test with $180^{\circ}$ stripping was carried out as per ASTM D 1876. Peel test involves 
stripping away of substrate joined by the adhesive. The substrates (glass paper, cotton and polyester) were flexible enough to permit a $180^{\circ}$ turn near the point of loading. Peel strength values are recorded in Newton per millimeter $(\mathrm{N} / \mathrm{mm})$ of width of the bonded specimen.

\section{Results and Discussion}

\subsection{TEM Analysis}

Transmission Electron Microscopy (TEM) is a vital characterization tool for directly imaging nanomaterials to obtain quantitative measures of grain size, size distribution, and morphology. TEM of ZnSe nanoparticles are shown in Figure 1. The image reveals that the shape of the particles is spherical and the average size of particles is about $80 \mathrm{~nm}$. The dark images show that nanoparticles are solid in structure.

\subsection{FT-IR Spectroscopy}

The FTIR spectra of the ZnSe/EVA nanocomposites are shown in Figure 2. The comparison of pristine, 2\% and $4 \% \mathrm{ZnSe}$ has been compared and the polymetric group identification with the effect of $\mathrm{ZnSe}$ in EVA could be established. The peaks due to the adsorbed acetate species cannot be clearly distinguished in the ZnSe/EVA spectra. This could be due to the presence of the EVA matrix in which the ZnSe nanopaiticles are dispersed. The peak at $1121.91 \mathrm{~cm}^{-1}$ observed on $4 \% \mathrm{ZnSe} / \mathrm{EVA}$ corresponds to the C-O group carboxylic derivates may be due to residue of Zinc acetate used in the reaction. The peak at $608 \mathrm{~cm}^{-1}$ represents the out of plane bending of $\mathrm{C}-\mathrm{H}$ alkenes and the peak at $3434.72 \mathrm{~cm}^{-1}$ is the characteristics absorption peak of $\mathrm{ZnSe}$, authenticates that the preparation technique is faithful. The stretching vibrations of $\mathrm{C}-\mathrm{H}$ alkanes are contributed the transmittance peaks at $2920 \mathrm{~cm}^{-1}$ and $2850.28 \mathrm{~cm}^{-1}$. The changes in the relative intensities of the bands in the region 1464 $\mathrm{cm}^{-1}, 1427 \mathrm{~cm}^{-1}$ and $1121 \mathrm{~cm}^{-1}$ in composite can be due to the presence of absorbed species on the surface of the $\mathrm{ZnSe}$ nanoparticles.

\subsection{Refractive Index Studies}

The refractive index of EVA/ZnSe has been determined using the measurement of dielectric constant with the help of LCR Impedance analyzer, by Maxwell's rule [16] [17].

$$
n=\sqrt{\left(\varepsilon_{r} \cdot \mu_{r}\right)}
$$

where $\varepsilon_{r}$ is the relative permittivity and $\mu_{r}$ is the relative permeability. $\mu_{r}$ is 1 for non-magnetic materials. The dielectric constant of the sample is calculated using the relation

$€_{\mathrm{r}}=\mathrm{Cd} / €_{0} \mathrm{~A}$; where the nanocomposite acts as a dielectric with $€_{0}$ the absolute permittivity, $\mathrm{C}$ is the capacitance, $\mathrm{d}$ is the thickness and $\mathrm{A}$ is the area $\left(\mathrm{mm}^{2}\right)$ of the $\mathrm{ZnSe} / \mathrm{EVA}$ composite. It is reported that EVA posses almost unchangeable index of refraction in entire electromagnetic region. In this study, we investigated the

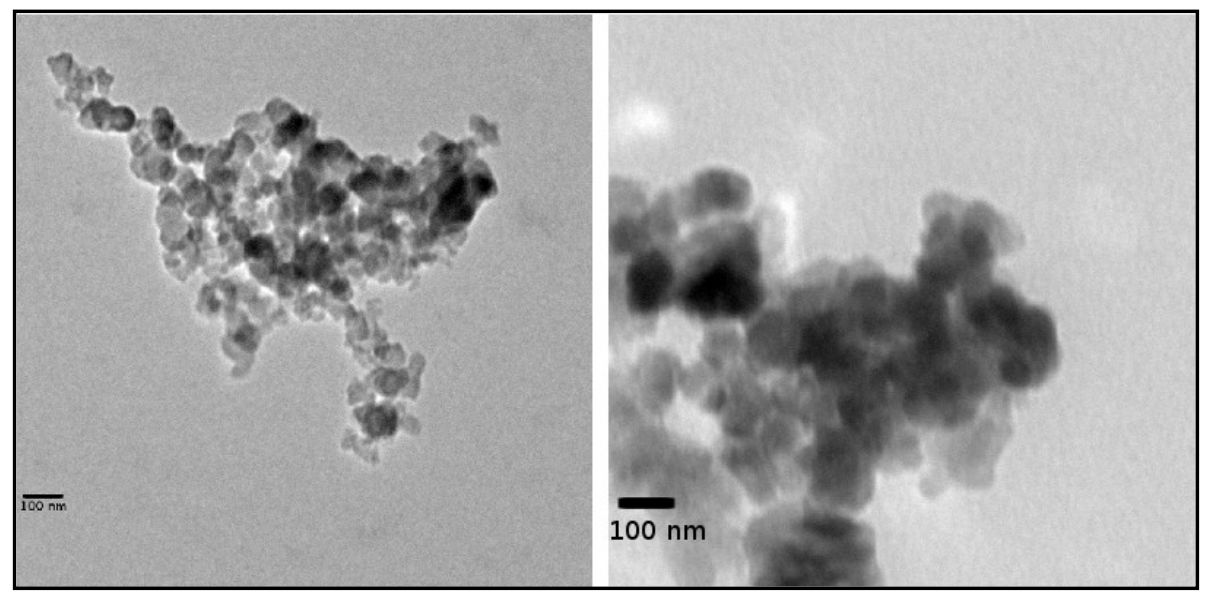

Figure 1. TEM image of ZnSe nanoparticles. 

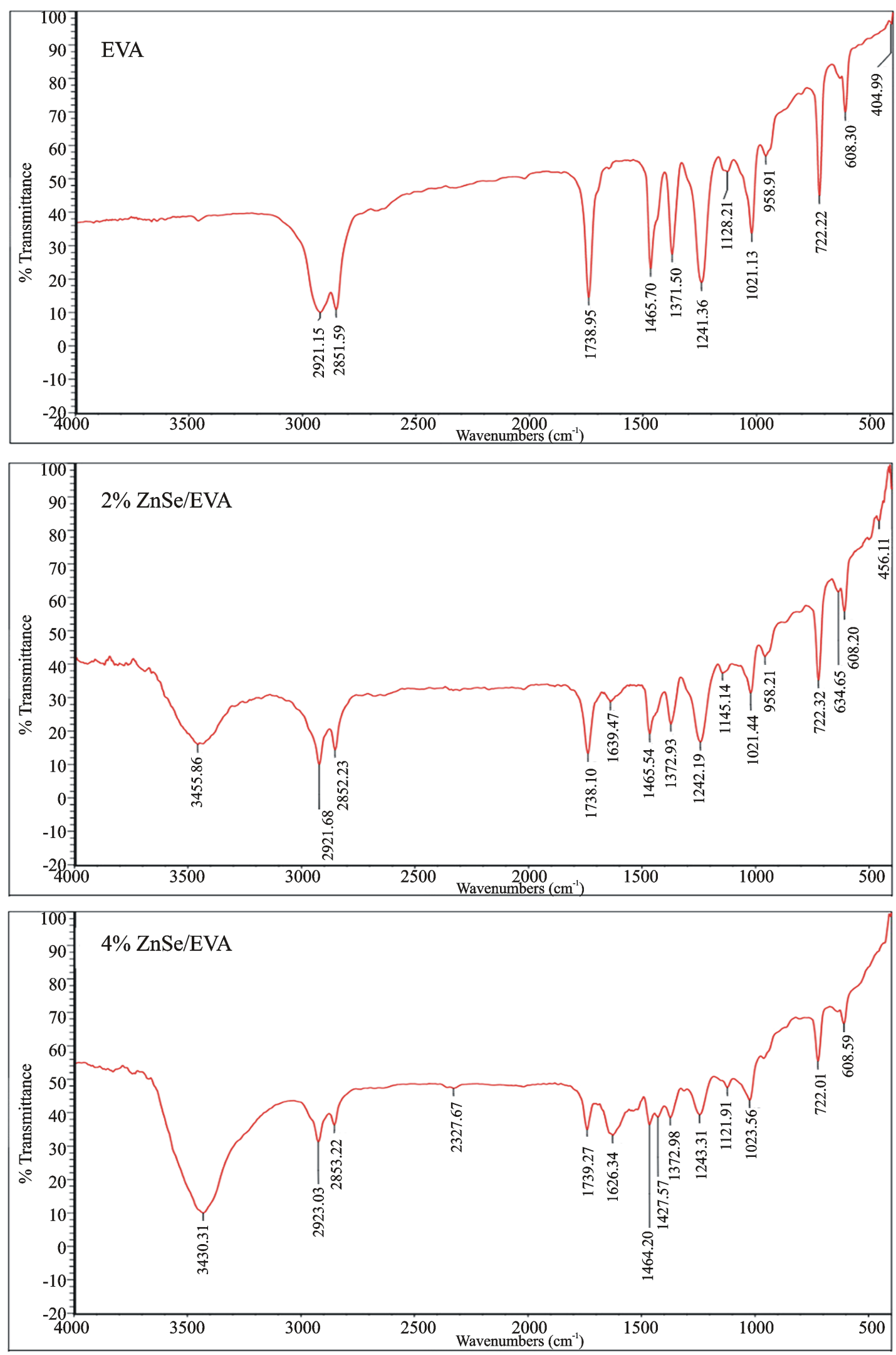

Figure 2. The comparison of FT-IR spectra of pure EVA, $2 \% \mathrm{ZnSe} / \mathrm{EVA}$ and $4 \% \mathrm{ZnSe} / \mathrm{EVA}$ nanocomposites. 
variation refractive index by varying frequency from $100 \mathrm{~Hz}$ to $1 \mathrm{MHz}$. The results of the variation of refractive index as a function of frequency for samples of different $\mathrm{ZnSe}$ nanoparticle concentration dispersed in EVA polymer matrix are shown in Figure 3. It is observed that the index value of pure EVA is 1.52 at room temperature and it increased to 2.28 as the concentration of $\mathrm{ZnSe}$ becomes $4 \%$. Commonly, the micro-structured coating of EVA and ZnSe/EVA nanocomposites allow a rough approximation for uniform index value in entire varied frequency region except for very low frequencies. It showed the value of index could go up to 5.7 below $500 \mathrm{~Hz}$. Figure 4 shows variation of refractive index with temperature. We examined the results using $4 \% \mathrm{ZnSe} / \mathrm{EVA}$ nanocomposite and showed that there should be a slight decrement in these values by increasing temperature. The calculations are carried out from room temperature to $353 \mathrm{~K}$ and sample possessed reproducibility.

In short, the average index profiles samples could be controlled from 1.52 to 2.28 by homogeneous dispersion of $\mathrm{ZnSe}$ nanoparticle in threshold concentration. The index difference of about 0.8 could be achieved easily from pristine matrix. By the inclusion of composites with different refractive indices, multi-layer anti-reflective coating and photovoltaic modules can be effectively modeled.

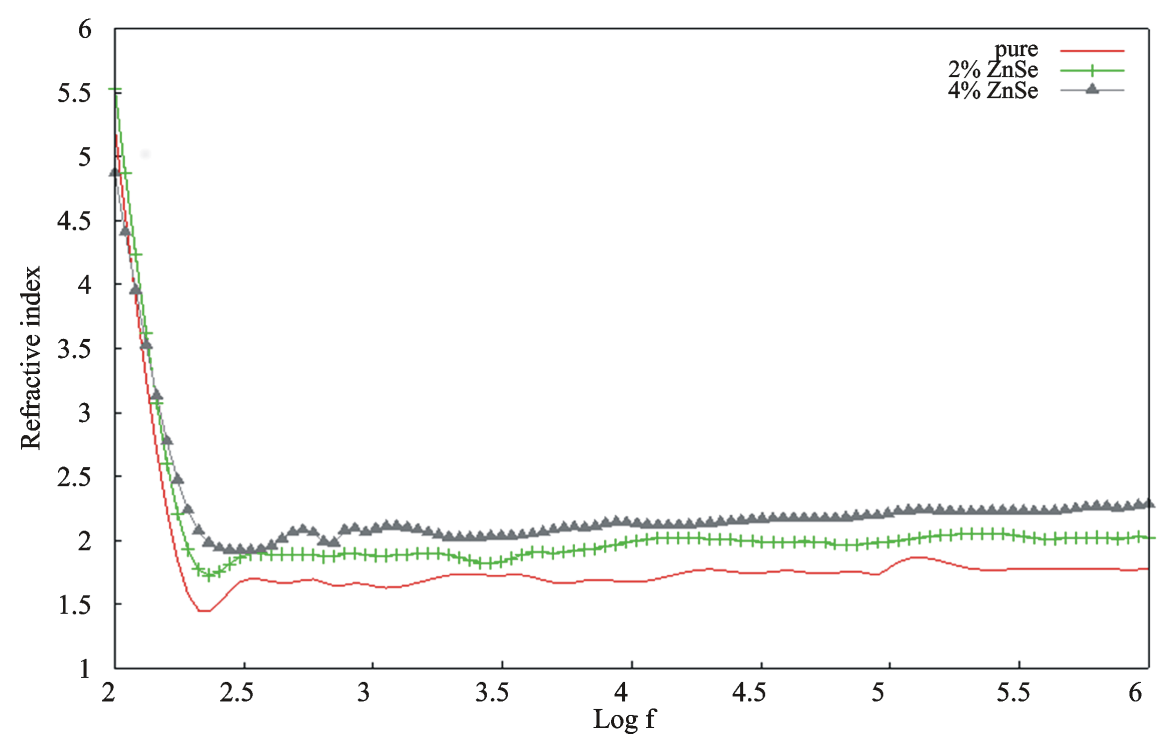

Figure 3. Plot showing the variation of refractive index as a function of frequency.

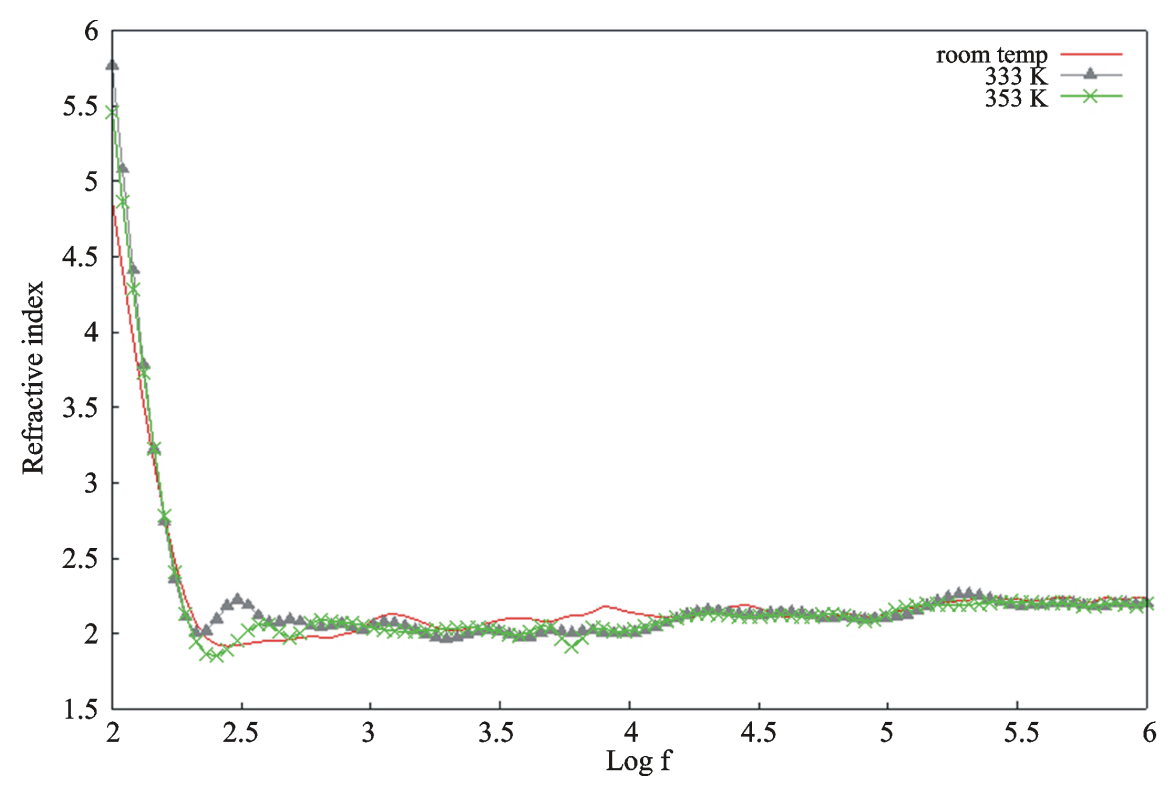

Figure 4. The graph of refractive index v/s $\log \mathrm{f}$ for different temperatures. 


\subsection{Optical Absorption Studies}

The UV-Vis-NIR spectra of the ZnSe/EVA nanocomposites are recorded in the region 200 to $2000 \mathrm{~nm}$ are shown in Figure 5. The bandgap of the prepared nanocomposites has been determined using the Tauc-relation [18]

$$
\alpha h v=K(h v-E g)^{n / 2}
$$

where $h v$ is the photon energy, $\alpha$ is the absorption co-efficient, Eg is the band gap, A is a constant and $\mathrm{n}=1$ for the direct band gap [19]. For allowed direct transition, a graph between $(\alpha h v)^{2}$ and $h v$ is plotted, extrapolation of the straight line to $(\alpha h v)^{2}=0$ axis gives the value of the band gap. It is shown in Figure 6. The estimated band gap of pure EVA and $2 \%$ and $4 \%$ ZnSe nanoparticles dispersed in EVA host matrix is found to be around 4.74 $\mathrm{eV}, 4.44 \mathrm{eV}$ and $4.08 \mathrm{eV}$ respectively. The band gap of the prepared composites showed a marked decrement when the percentage of nanoparticles is increased.

\subsection{TG-DTA Analysis}

EVA undergoes both physical and chemical changes while heating so that a clear distinctive thermal analysis is

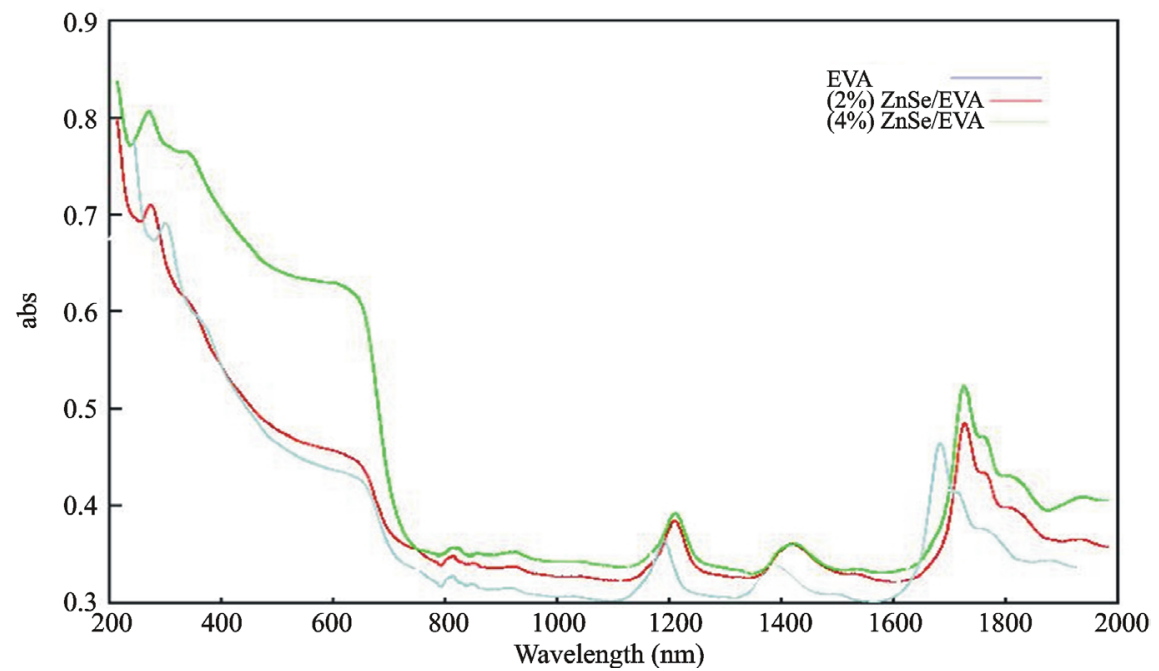

Figure 5. UV-Vis-NIR Spectra of EVA and ZnSe/EVA nanocomposites.

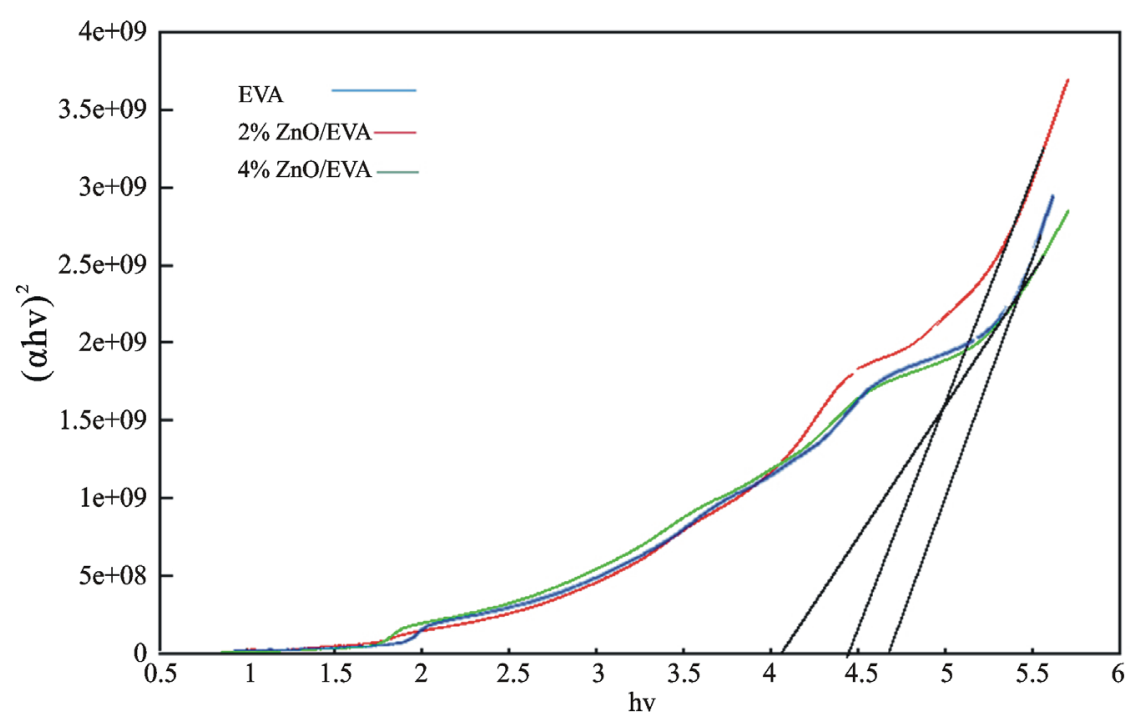

Figure 6. The band gap variation of EVA along with ZnSe/EVA nanocomposites. 
needed. The Thermogravimetric (TG) and Differential Thermal Analysis (DTA) on pure and composite EVA polymer are carried out between room temperature to $500^{\circ} \mathrm{C}$. The TG-DTA traces of pure and doped samples are shown in Figures 7(a)-(c). It seemed nearly same behaviour for three samples with two steps decomposition between $290^{\circ} \mathrm{C}$ to $500^{\circ} \mathrm{C}$. It is clear that the Pure EVA is thermally stable up to $298^{\circ} \mathrm{C}$ whereas $2 \% \mathrm{ZnSe}$ and $4 \%$ $\mathrm{ZnSe}$ doped EVA is stable upto $309^{\circ} \mathrm{C}$ and $315^{\circ} \mathrm{C}$ respectively. Thus the thermal stability of the EVA nanocomposite increased with increasing the filler concentrations. $28.5 \%$ of weight lost in the first stage decomposition of Pure EVA, but once can easily found from the thermogram that the weight loss in the first stage decomposition decreases as filler concentration increases and found to be $17.3 \%$ and $14.2 \%$ for $2 \%$ and $4 \% \mathrm{ZnSe} / \mathrm{EVA}$ respectively.

\subsection{Mechanical Properties}

The virgin EVA samples showed tensile strength in the range of 29 - $31 \mathrm{MPa}$, with $430 \%$ elongation. The effect of nano $\mathrm{ZnSe}$ on tensile strength and elongation at break is shown in Figure 8. The 2\% addition of ZnSe nanoparticle found to reduce the tensile properties of the composite compared to the virgin compound. The reduction of tensile strength at higher ratio of nano loading was due to the stress concentration at the interface ZnSe particles agglomerates. As the loading level increases the effect of dispersion and distribution of nanomaterials gets reduced. Percentage stretch possible with the nanocomposite samples reduces with $\mathrm{ZnSe}$ loading. This phenomenon is already reported with polymer based nanocomposites as the matrix molecular orientation is negatively affected with the reinforcement particles [20].

The peel strength increases for EVA-ZnSe composites on all substrates on $2 \%$ incorporation. The adhesion properties differs, based on the molecular interactions of the adhesive with the adherent. Figure 9 shows peel strength of the nanocomposite with different ratios of ZnSe. It is observed that the molecular flexibility of EVA is not affected by $2 \%$ of $\mathrm{ZnSe}$ on all substrates. The improvement in cohesive strength resulting from the presence of $\mathrm{ZnSe}$ might be responsible for the improvement in peel strength. The lack of distribution with increased amount of nano particles might be the underlying reason for the drastic reduction of peel strength at $4 \%$ loading. It can also be inferred that there is a maximum ratio $(2 \%)$ for $\mathrm{ZnSe}$, above which the inherent polymer property is adversely affected.

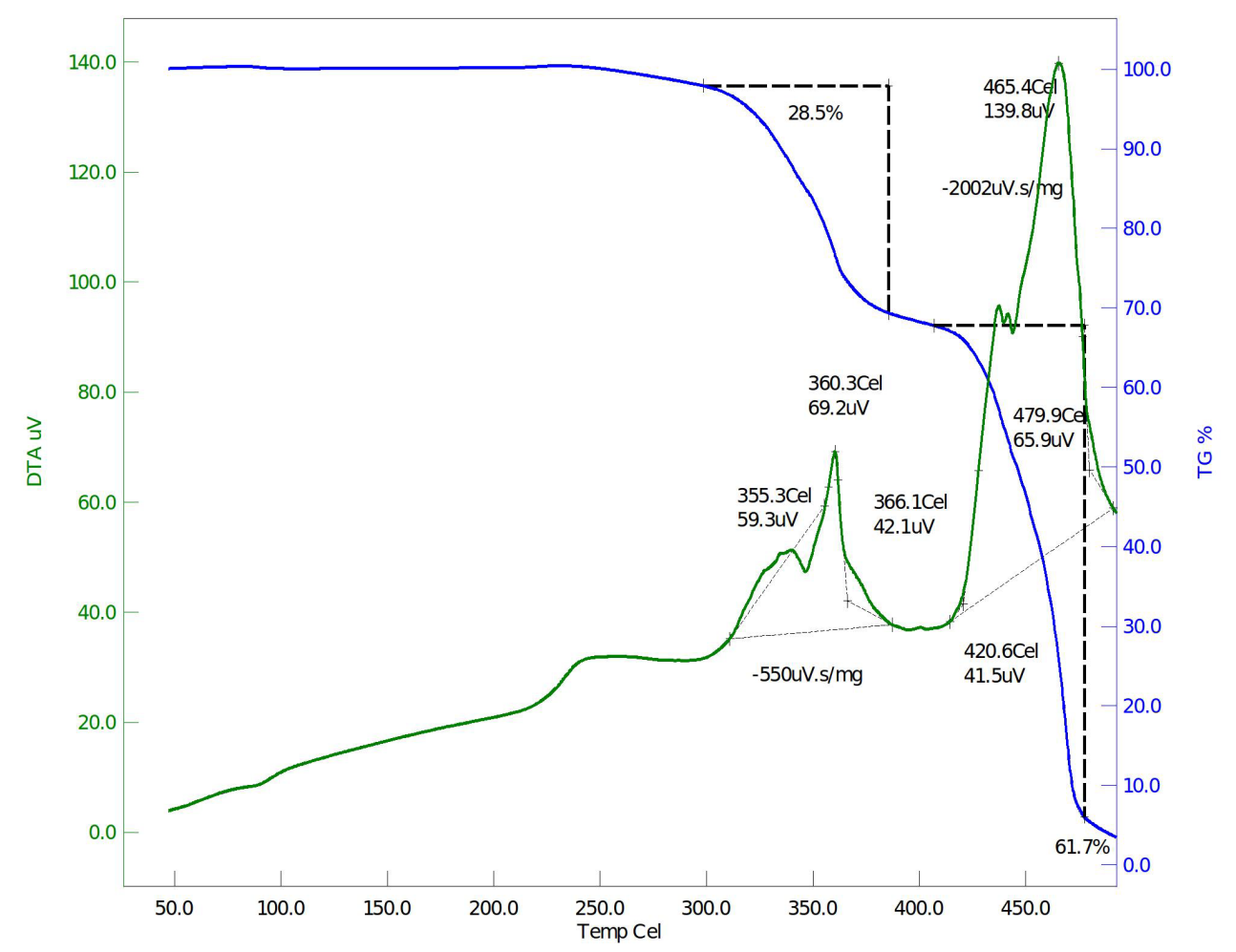

(a) 


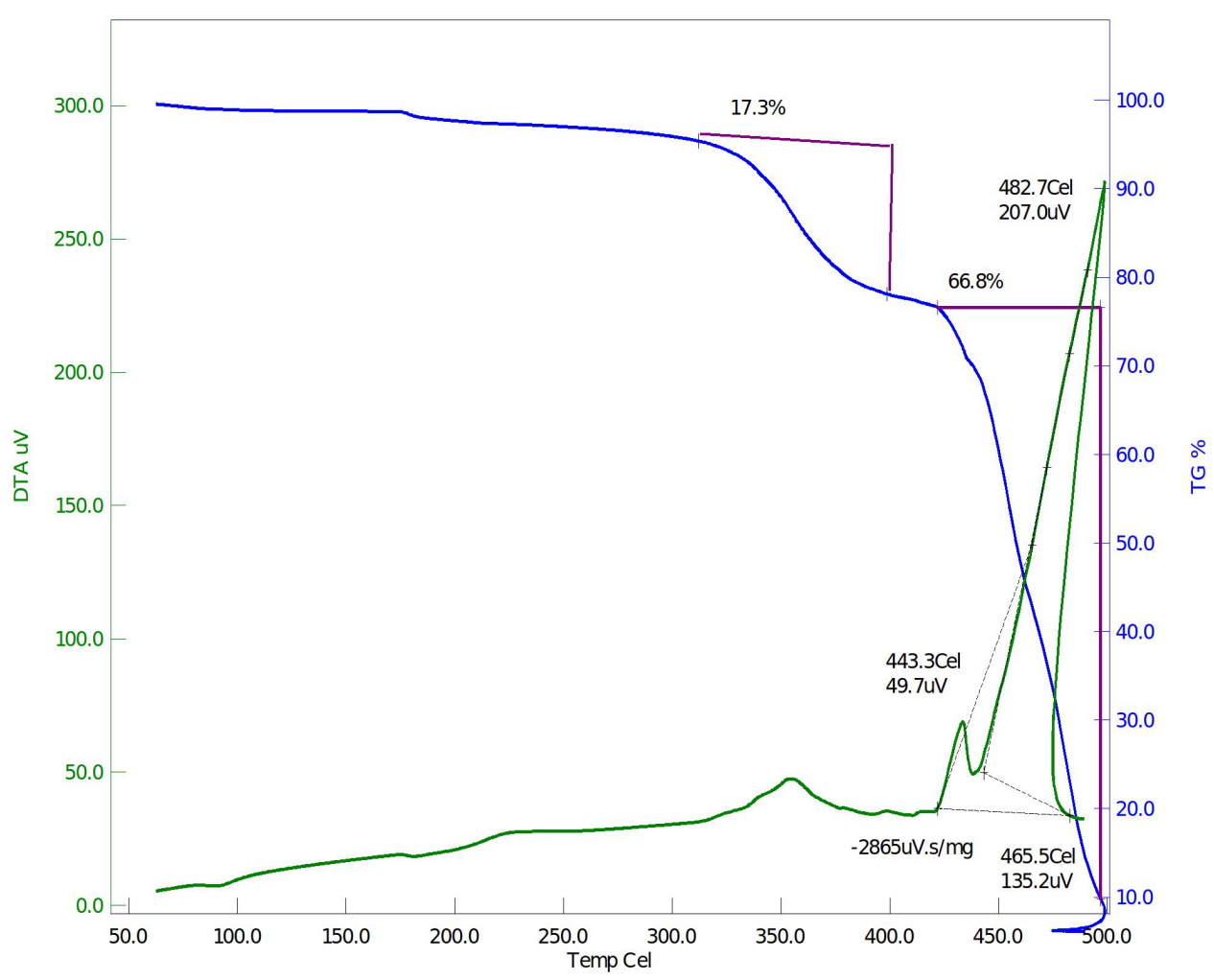

(b)

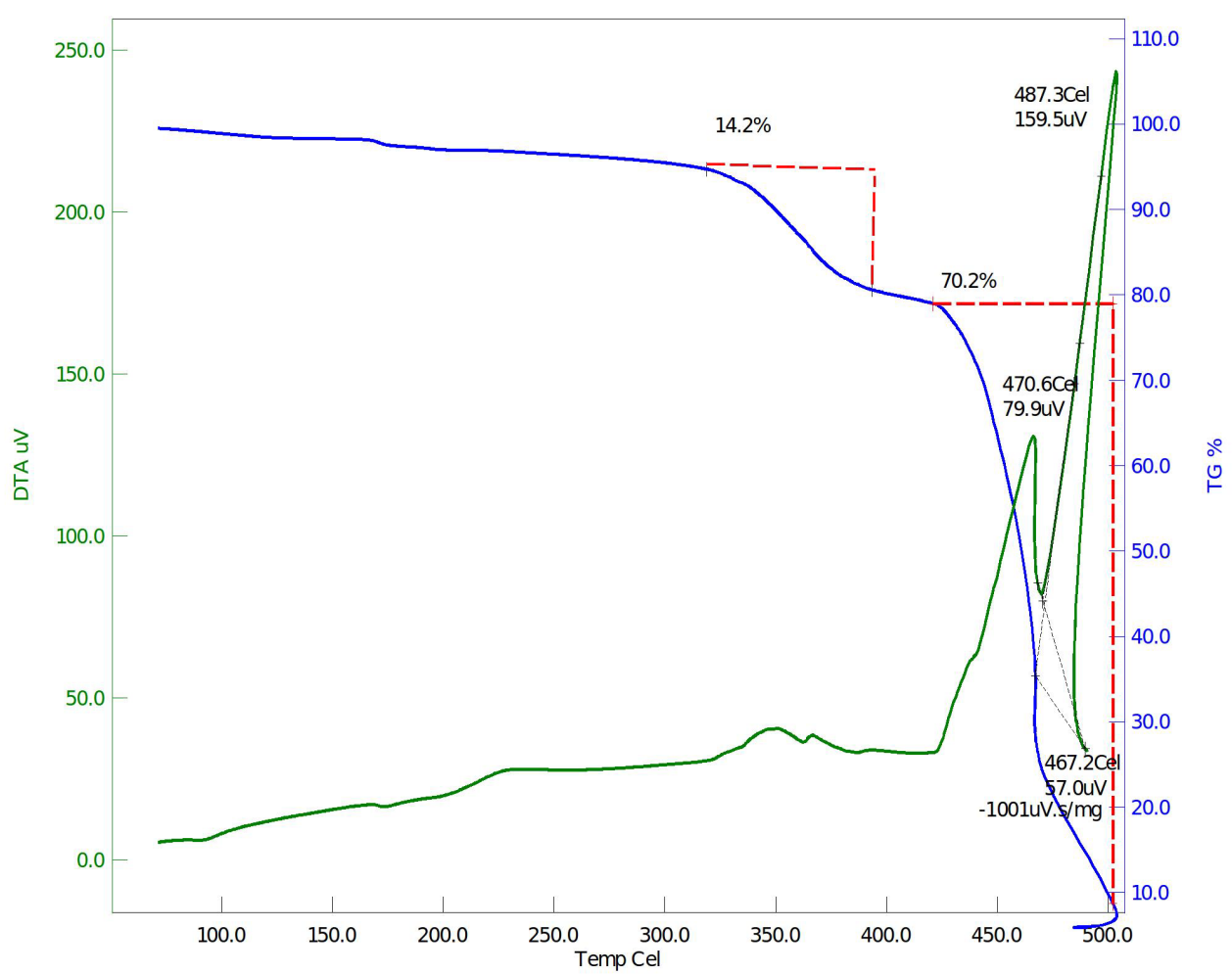

(c)

Figure 7. (a) TG-DTA Curve of EVA co-polymer; (b)TG-DTA Curve of $2 \% \mathrm{ZnSe} / \mathrm{EVA}$ nanocomposite; (c)TG-DTA Curve of $4 \% \mathrm{ZnSe} / \mathrm{EVA}$ nanocomposite. 


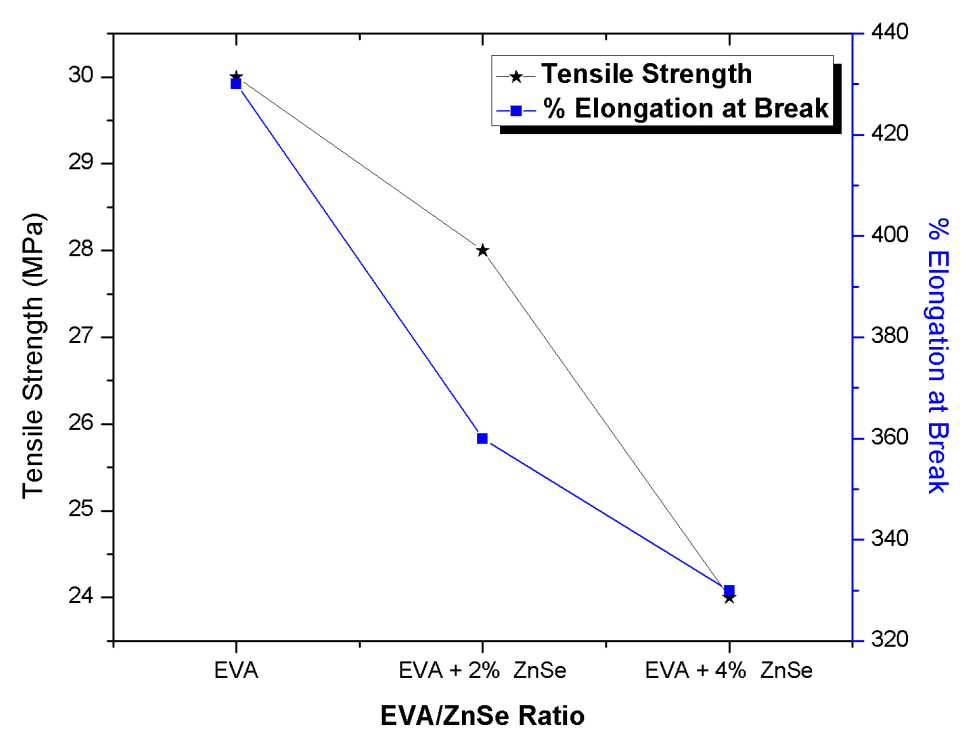

Figure 8. Comparison of tensile strenth and \% elongation with various concentration of $\mathrm{ZnSe}$ filler in EVA.

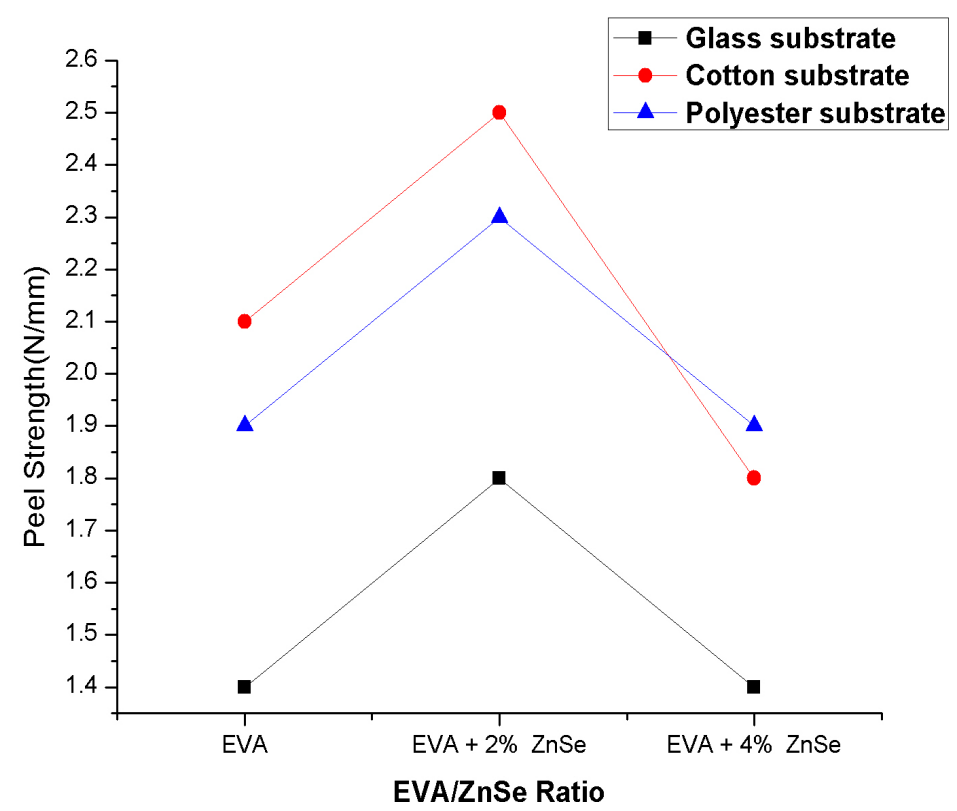

Figure 9. Plot showing the peel strength of EVA/ZnSe nanocomposites on various substrate.

\section{Conclusion}

A facile approach towards the synthesis of ZnSe nanoparticles and ZnSe/EVA nanocomposites was established. The synthesized particle's size was estimated as $80 \mathrm{~nm}$. FT-IR analysis confirmed the presence of polymetric group of EVA, compared with its composites and corroborated the presence of $\mathrm{ZnSe}$ particles. The value of index of refraction of the composite could be easily controlled by varying the amounts of dispersed ZnSe nanoparticles. The band gaps of the pure, $2 \%$ and $4 \% \mathrm{ZnSe} / \mathrm{EVA}$ were found to be $4.74 \mathrm{eV}, 4.44 \mathrm{eV}$ and $4.08 \mathrm{eV}$ respectively, thereby increasing the conductivity of the EVA with increasing the filler concentrations. The thermal stability of the samples increases with increasing the filler concentrations. The mechanical properties of the samples were also studied. The tensile strength and peel strength of the nanocomposites increase initially and drop down with $\mathrm{ZnSe}$ filler loading. 


\section{Acknowledgements}

One of the authors is thankful to Department of Science and Technology, New Delhi, India for granting the fund to carry out the research.

\section{References}

[1] Zhu, J.H., Chen, M.J., Qu, H.L., Zhang, X., Wei, H.G., Luo, Z.P., Colorado, H.A., Wei, S.Y. and Guo, Z.H. (2012) Interfacial Polymerized Polyaniline/Graphite Oxide Nanocomposites toward Electrochemical Energy Storage. Polymer, 53, 5953-5964. http://dx.doi.org/10.1016/j.polymer.2012.10.002

[2] Thurn Albrecht, T., Schotter, J., Kastle, G.A., Emley, N., Shibauchi, T., Krusin Elbaum, L., Guarini, K., Black, C.T., Tuominen, M.T. and Russell, T.P. (2000) Ultrahigh-Density Nanowire Arrays Grown in Self-Assembled Diblock Copolymer Templates. Science, 290, 2126-2129.

[3] Pyun, J. and Matyjaszewski, K. (2001) Review Previous Article Next Article Table of Contents Synthesis of Nanocomposite Organic/Inorganic Hybrid Materials Using Controlled/“Living” Radical Polymerization. Chemistry of Materials, 13, 3436-3448. http://dx.doi.org/10.1021/cm011065j

[4] Brabee, C.J., Sariciftci, N.S. and Hummelen, J.C. (2001) Plastic Solar Cells. Advanced Functional Materials, 11, $15-26$. http://dx.doi.org/10.1002/1616-3028(200102)11:1<15::AID-ADFM15>3.0.CO;2-A

[5] Blom, P.W.M., Schoo, H.F.M. and Matters, M. (1998) Electrical Characterization of Electroluminescent Polymer/ Nanoparticle Composite Devices. Applied Physics Letters, 73, 3914. http://dx.doi.org/10.1063/1.122934

[6] Kiesow, A., Morris, J.E., Radehaus, C. and Heilmann, A. (2003) Switching Behavior of Plasma Polymer Films Containing Silver Nanoparticles. Journal of Applied Physics, 94, 6988. http://dx.doi.org/10.1063/1.1622990

[7] Subbaiah, Y.P.V., Prathap, P., Devika, M. and Reddy, K.T.R. (2005) Close-Spaced Evaporated ZnSe Films: Preparation and Characterization. Physica B: Condensed Matter, 365, 240-246. http://dx.doi.org/10.1016/j.physb.2005.05.020

[8] He, T., Wang, C., Pan, X. and Wang, Y. (2009) Nonlinear Optical Response of Au and Ag Nanoparticles Doped Polyvinylpyrrolidone Thin Films. Physics Letters A, 373, 592-595. http://dx.doi.org/10.1016/j.physleta.2008.12.002

[9] Ma, G., He, J. and Tang, S. (2003) Femtosecond Nonlinear Birefringence and Nonlinear Dichroism in $\mathrm{Au}_{\mathrm{TiO}} \mathrm{Com}^{\mathrm{C}}$ posite Films. Physics Letters A, 306, 348-352. http://dx.doi.org/10.1016/S0375-9601(02)01626-2

[10] Gonzalex-Benito, J., Castillo, E. and Caldito, J.F. (2013) Coefficient of Thermal Expansion of $\mathrm{TiO}_{2}$ Filled EVA Based Nanocomposites. A New Insight about the Influence of Filler Particle Size in Composites. European Polymer Journal, 49, 1747-1752. http://dx.doi.org/10.1016/j.eurpolymj.2013.04.023

[11] Kasap, S. and Capper, P. (2007) Springer Handbook of Electronic and Photonic Materials. Springer, Berlin. http://dx.doi.org/10.1007/978-0-387-29185-7

[12] Rhee, S.H. and Choi, J.Y. (2002) Preparation of a Bioactive Poly(methyl methacrylate)/Silica Nanocomposite. Journal of the American Ceramic Society, 85, 1318-1320. http://dx.doi.org/10.1111/j.1151-2916.2002.tb00269.x

[13] Camargo, P.H.C., Satyanarayana, K.G. and Wypych, F. (2009) Nanocomposites: Synthesis, Structure, Properties and New Application Opportunities. Materials Research, 12, 1-39. http://dx.doi.org/10.1590/S1516-14392009000100002

[14] Homann, T., Hotje, U., Binnewies, M., Borger, A., Becker, K.D. and Bredow, T. (2006) Composition-Dependent Band Gap in $\mathrm{ZnS}_{x} \mathrm{Se}_{1-x}$ : A Combined Experimental and Theoretical Study. Solid State Sciences, 8, 44-49. http://dx.doi.org/10.1016/j.solidstatesciences.2005.08.015

[15] Hodes, G. (2004) Chemical Solution Deposition of Semiconductor Films. Taylor and Francis, New York, 362.

[16] Ashcroft, N.W. and Mermin, N.D. (2011) Solid State Physics. 11th Indian Reprint, Brooks/Cole, Pacific Grove.

[17] http://large.stanford.edu/courses/2007/ap272/brockman1

[18] Tauc, J. (1974) Amorphous and Liquid Semiconductor. Plenium Press, New York. http://dx.doi.org/10.1007/978-1-4615-8705-7

[19] Kumar, S. and Chandra, R. (2005) Temperature Dependent Studies of CdS Nanoparticles in Viscous Matrix. Optical Materials, 27, 1346-1349. http://dx.doi.org/10.1016/j.optmat.2004.09.015

[20] Hasegawa, N., Okamoto, H., Kawasumi, M. and Usuki, A. (1999) Preparation and Mechanical Properties of Polystyrene-Clay Hybrids. Journal of Applied Polymer Science, 74, 3359-3364. http://dx.doi.org/10.1002/(SICI)1097-4628(19991227)74:14<3359::AID-APP9>3.0.CO;2-2 